\title{
Architectural Composition and Zeitgeist
}

\author{
Armen S. Sardarov ${ }^{1, *}$ \\ ${ }^{I}$ Architectural Faculty, Belarusian National Technical University, Minsk, Belarus \\ ${ }^{*}$ Corresponding author. Email: sardarov@bntu.by
}

\begin{abstract}
The use in architecture of certain compositional techniques was always connected with the ideology dominating in the society. Regularity, static character, symmetry or imbalance, dynamics expressed the notion great Goethe called Zeitgeist - time spirit.
\end{abstract}

Keywords: Composition, Rhythm, Symmetry, Spirit of time.

\section{INTRODUCTION}

Spatial environment arranged and governed by human, provides the conditions for human lifesustaining activity. At the same time, this environment affects humans, forms their visual impressions, determines the character of psychological reactions and physical actions. Of primary importance is the fact that initially "empty" natural space is arranged, developed, streamlined.

\section{ANCIENT IDEA OF COMPOSITION}

Human great mythologies and religions reflect this transition. Ancient Greek poet Hesiod in his "Theogony" writes that at first there was "chaos" [Theog. 116]. The same idea is present in the Old Testament: "Earth was waterless and bare..." [Genesis, chapter 1, 2]. Then heavenly actions followed to reorganize this chaos, to fill the void. In this overarching idea of appearance of organized world there is a thought about the introduction of order, a system into the world. That was exactly what the first architects of humanity were doing ("Figure 1"a, b).

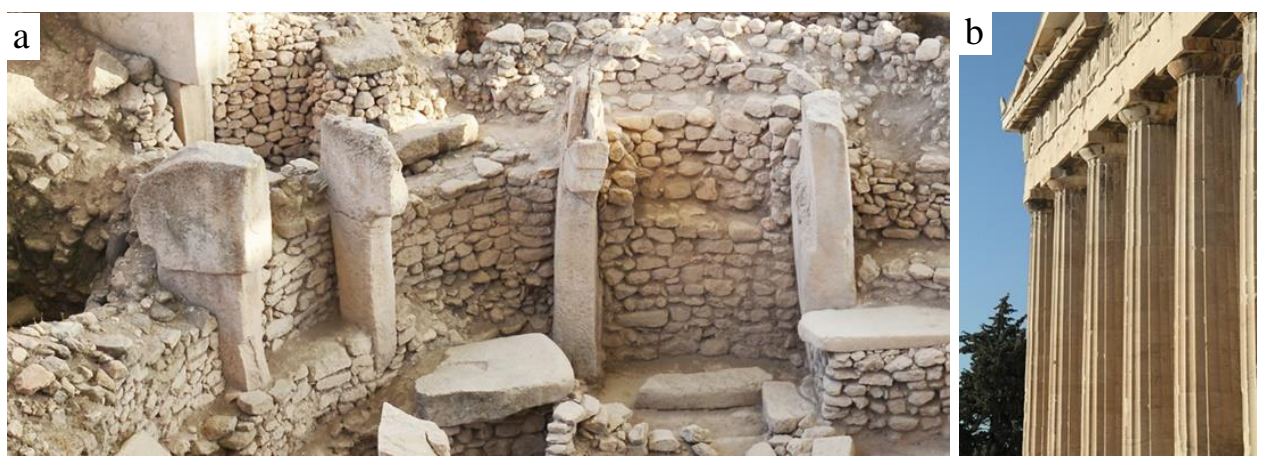

Figure 1 Ancient buildings with used architectural composition. a - Gobokli-Tepe. Turcey. b - Parthenon. Greece.

In the oldest constructions we can notice the first compositional techniques, i.e. spatial stability based on the correlation of load-bearing and suspended elements and regularity of recurrence, e.g. recurrence of supports or masonry.
These both constructive and compositional techniques became the main principles and ideas of architecture. Such compositional principles as balance, symmetry, regular recurrence were used not only in architecture but also in other arts, e.g. visual arts (ornamental rhythm), music, poetry 
(stress, rhyme) etc. These compositional elements had an impact on a person, created a psychological comfort, feeling of recognition and confidence.

These principles of external "order" become important not only in arts but in the arrangement of human communities, even states. That is what Plutarch writes about it: "Phalet did the same as the best legislators. His songs appealed to obedience and conformity through melodies and rhythms which contain some organized order" [Vitae parallelae, Lycurgus, 4]. Moreover, it was believed that "discordant and wrong sounds can cause disintegration of the state" [Ib, Agidius, 10].

\section{EPOCHS OF CHANGES IN THE HISTORY OF ARCHITECTURE}

Thus, in architecture as well as in other spheres of life, "order", "system", "balance", "regular recurrence" become important principles and even embody "higher forces" which govern people. Compositional elements acquire importance in the functioning of the system, i.e. LIFE OUTLOOK WORLD PERCEPTION - INDIVIDUAL SOCIETY. It's no wonder that in historical epochs of changes, rebuilding the implementation of these principles loses its importance and even becomes impossible. It refers to architecture, which renders Zeitgeist in the best way possible. It was in the epoch of "riot of Baroque" which reflected the struggle between Catholicism and Reformation, when austere and balanced classical forms of the Renaissance acquired curves and decorative components.

The development of the European civilization in the XVI-XVII centuries took place while the Christian religion in its Western Catholic form was dominating. However, at that time Catholicism was in conflict with Reformation which was the basis of Protestantism. The same time was the period of the development of civic sciences, i.e. philosophy, physics, mathematics, astronomy (Descartes, d'Espinoza, Newton, Kepler and others).

Social and economic base had also changed. Although absolutism and feudal social structure was still dominant, craft activity and market relations were developing.

It was this social, economic and intellectual context that changed the character of people's world perception, which found its reflection in arts and architecture. Classical traditions expressed in
Renaissance with its recognizability and "correctness" of forms, were challenged. Variability, imbalance, dynamics appeared. Architectural forms of the buildings with geometrically straight walls, cornices, gable, frontons while remaining in the former compositional limits, started to crook and "swim into endlessness"...

New forms still served as a psychological message to a person aimed at attracting attention and even domination. The researcher writes that baroque forms "fascinate, stupefy, smash" [1]

In the XVII-XVIII centuries an important role in the process of impact on people was played by synthesis of architecture with painting sculpture, decorative arts (ornamental patterns, stucco etc.). The degree of this synthesis is evaluated by the scientist: "Architecture became sculptural, sculpture became part of architecture" [2].

The end of XIX - early XX centuries is characterized by great changes in geopolitical, social, economic and cultural life the people. National and class antagonism between and within the states aggravated, which led to wars and revolutions. Changes took place in the world of literature, arts, architecture. The creators started to move from classical, "correct" forms to experiments with composition, colours, shapes. Thus, trends of the style which is called avant-garde appeared, i.e. futurism, constructivism, modernism, abstract art.

Dynamics and unbalance of avant-garde started to destroy the habitual stability and regular recurrence of architectural forms. Titus Burckhardt spoke about it when he specified the universal character of rhythm: "Strictly speaking, rhythm does not belong to space but time. Therefore, rhythm is not a quantitative category, but a qualitative one" [3].

\section{IDEAS OF XX - XXI CENTURIES}

Deep connection between architectural style, social and cultural state of the society can be traced by the architectural development of the capital of Belarus, Minsk, in the XX- XXI centuries. The 20s30 s of the last century were characterized by postrevolutionary upheaval, social dynamics. This atmosphere, i.e. Zeitgeist, added to the architecture of buildings imbalance, irregular rhythm of structures and fenestration ("Figure 2"a, b). 


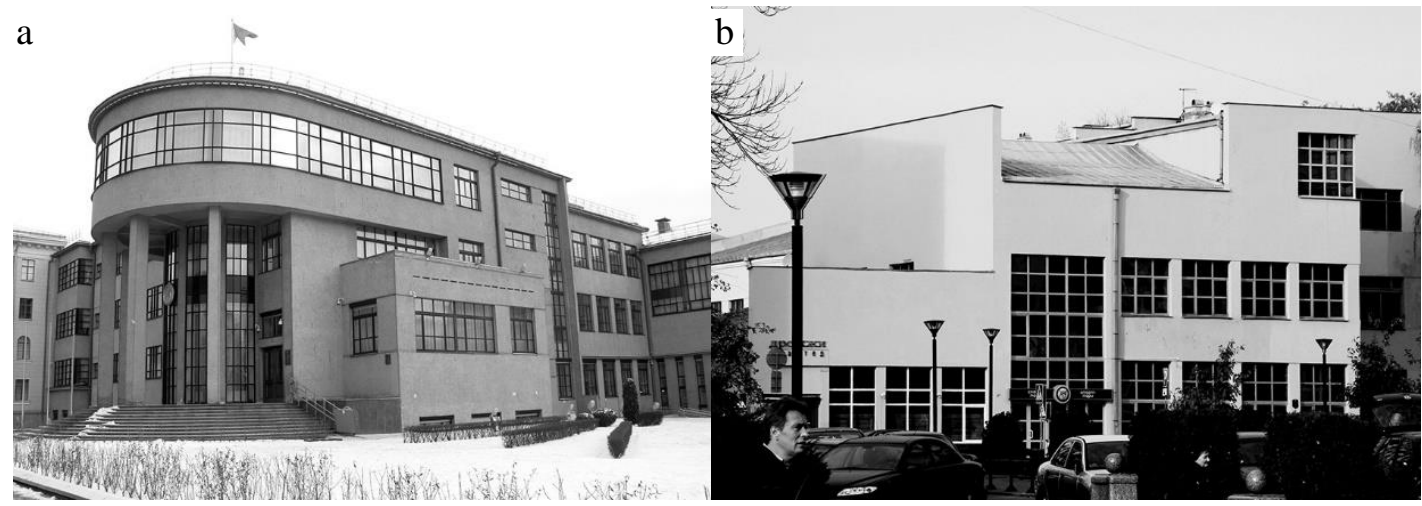

Figure 2 Buildings in Constructivism style. Minsk. Belarus.

It is known that by the 30 s social climate started to change. The movement to the stability of the state encouraged the famous architect Iosif
Langbard to design a building in which separated constructivist structures combine $\mathrm{d}$ in symmetrical composition. ("Figure 3"a, b).

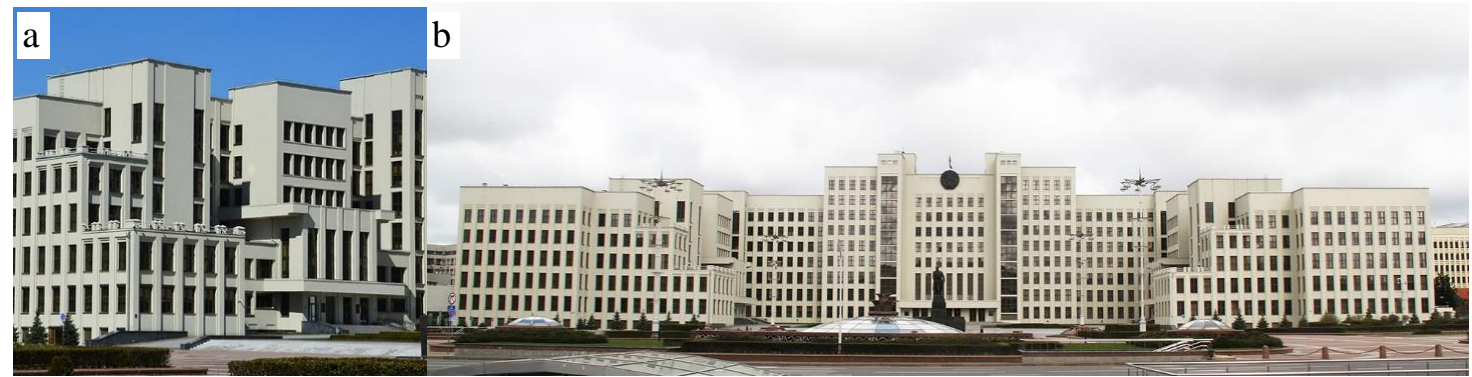

Figure 3 Work of architect Langbard "Government House”. Minsk. Belarus.

Another radical change took place at the end of the 40s when strife for stability found its expression in neo-classical architecture. This is clearly seen in the architecture of if the main thoroughfare of the city (Prospect of Stalin, Lenin, Francisk Skarina, Independence now). This is what a Belarusian art expert writes about the spirit of its architecture: "Large scale of solid buildings which firmly barrier the mainstream of the avenue, convey a sense of steady composure. The building outlines are austere and clear-cut" [4].

In these ensembles of the 40s-50s of special importance were classical decisions of facades with portico - like excerpts from classical antiquity with their "faces of gods" which were embodied by these facades. Axial symmetry, balanced forms created the feeling of confidence and composure which was required by the spiritual atmosphere of society ("Figure 4"a, b). The connection between a dominating style and social state is well described by talented philosopher and psychologist Carl Gustav Jung: "What is realism and naturalism for the epoch? What is romanticism? These are art trends, which expressed the notions most required by the spiritual atmosphere" [5]. 


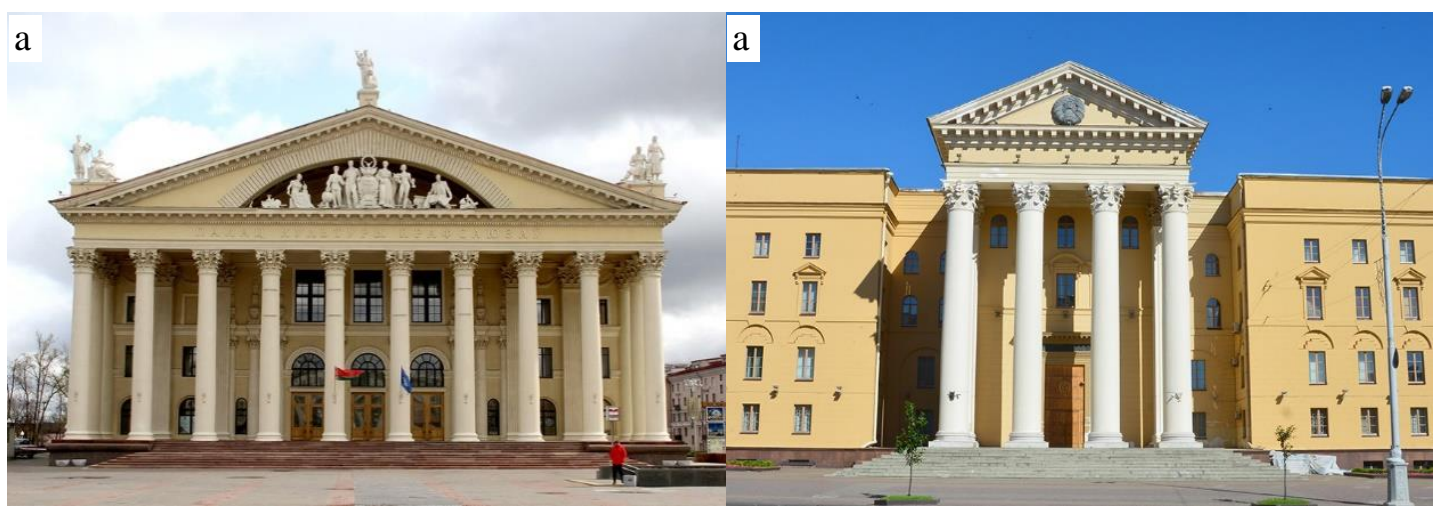

Figure 4 Classic ideas in XX century. Minsk. Belarus.

But as early as at the end of the 80 s the society aspired after stability, permanence which is represented by the architecture of the Palace of Independence. In its composition there is axial symmetry, the rhythm of columns is austere and clear-cut as if calling for preservation of spiritual atmosphere on the eve of perestroika ("Figure 5").

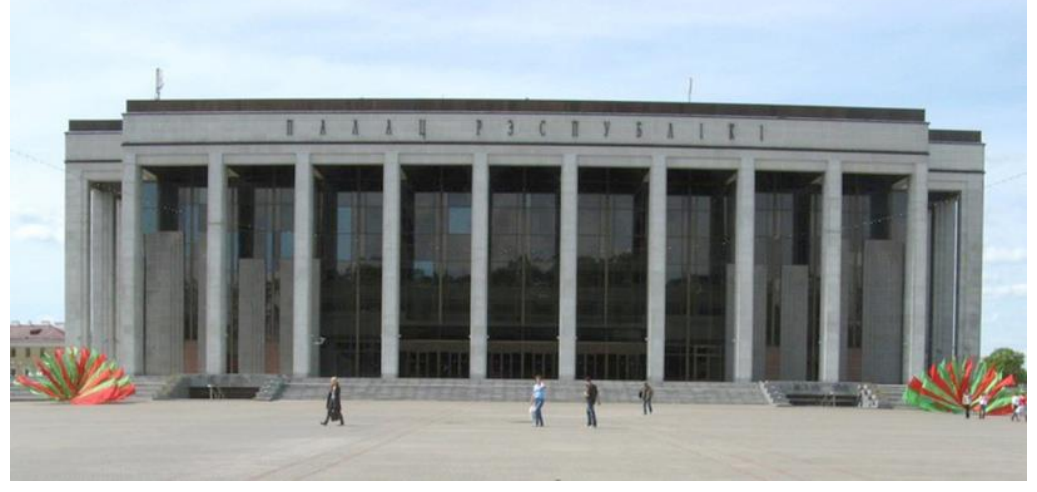

Figure 5 Neo-classic idea in XXI century. Minsk. Belarus.

\section{CONCLUSION}

The beginning of the XXI century with its reevaluation, life outlook and world perception created "spiritual microclimate" for the appearance of new architecture. Stability and steady rhythm became irrelevant. The rhythm of window aperture is broken. Composition of structures loses their balance and creates dynamic tension ("Figure 6"a, b, c). Therefore, by means of symbolic compositional and artistic language architecture once again expresses world perception of its epoch, thus embodying Zeitgeist.
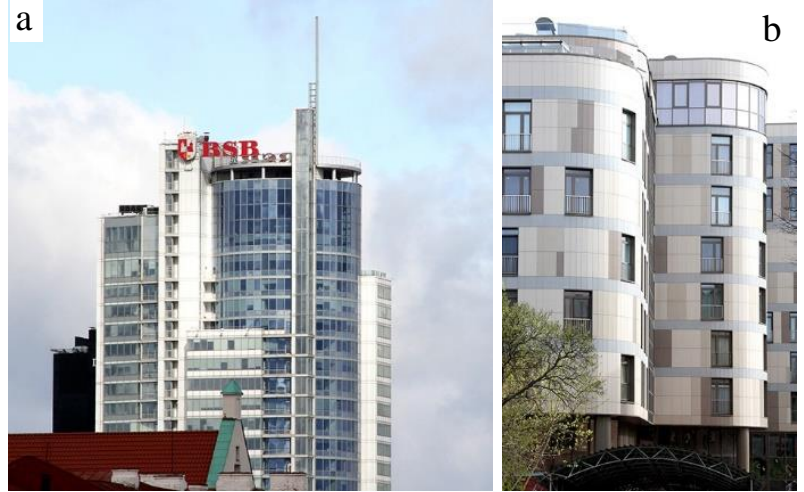

$\mathrm{c}$

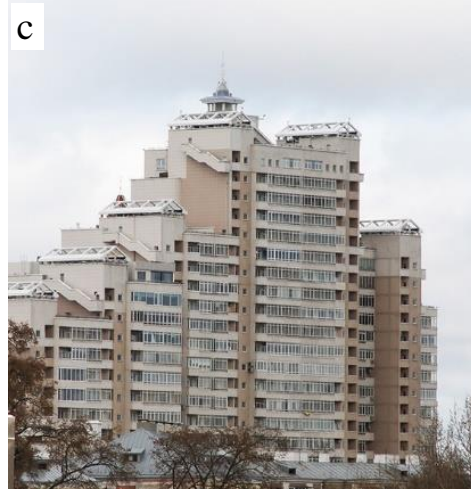

Figure 6 Non - balanced architecture of XXI century. Minsk. Belarus. 


\section{AUTHOR'S CONTRIBUTIONS}

This paper is independently completed by Armen S. Sardarov.

\section{REFERENCES}

[1] Meyer Peter. Historia Sztuki Europejskiej. T.2. -Warszawa: Panstwowe Wydawnictwo Naukowe. 1973. -317 p., p.143. (Translation A.S.).

[2] Pothorn Herbert. A Guide to Architectural Styles. Oxford: Phaidon Press, 1982. -253 p., , p.83.

[3] Burckhard Titus, The art of Islam. Language and meaning (Iskusstvo Islama. Yazyk i znachenie), per. s angl. Taganrog: IRBI, 2009, 288 p., p. 74.

[4] I.M. Elatomtzeva, Monumental chronicle of the era (Monumentalnaya letopis epohi). Mn.: Nauka I tehnica, 1969, 150 p., p. 76 [in Russian].

[5] Yung Karl Gustav, Archetype and symbol (Arhetip i simvol), per. s nem. пер. с нем. M.: Kanon, ROON "Reabilitazia", 2021, 336 p., pp. 303-304. 